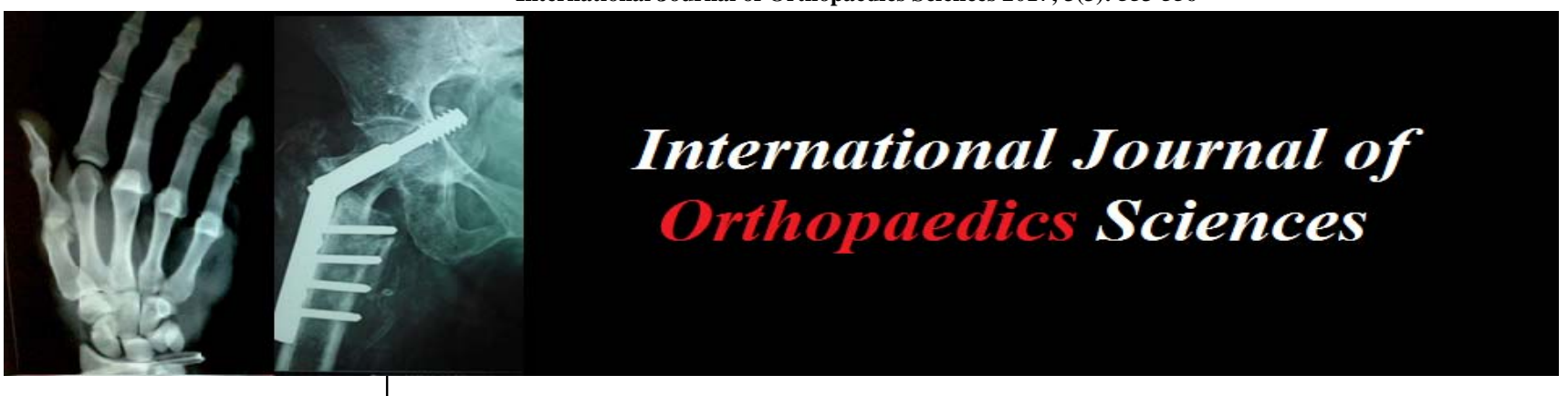

ISSN: $2395-1958$

IJOS 2017; 3(3): 553-556

(C) 2017 IJOS

www.orthopaper.com

Received: 28-05-2017

Accepted: 30-06-2017

Dr. Vijaya Mahanth Prasad K Assistant Professor, Department of Orthopedics, Navodaya Medical College, Raichur, Karnataka, India

Dr. Sanjeev Chincholi Professor, Department of Orthopedics, Navodaya Medical College, Raichur, Karnataka, India

\section{Management of fracture neck femur treated with bipolar hemiarthroplasty in the elderly population}

\author{
Dr. Vijaya Mahanth Prasad K and Dr. Sanjeev Chincholi
}

DOI: http://dx.doi.org/10.22271/ortho.2017.v3.i3h.90

\section{Abstract}

Background: Hip fractures are common and comprise about $20 \%$ of the operative workload of an orthopedic trauma unit. As life expectancy is increasing all over the world Geriatric population sustaining the Fracture neck of femur are also increasing resulting in Great burden to health of society which can be better managed with Hemiarthroplasty. The goal of the current study is to assess the functional outcome and quality of life in terms of pain, mobility, stability using Harris Hip Score

Aims and objective of the study: To study the results of bipolar prosthesis with respect to pain, mobility and stability and to analyze the complications per-operative and post operative like infection, DVT, acetabular erosion, loosening and dislocation.

Materials and methods: The prospective study included thirty patients with intracapsular femoral neck fractures referred to the Department of Orthopaedics, Ashwini Hospital, Gulbarga were selected for this study. Patients with intracapsular femoral neck fractures and aged above 55 years were considered.

Discussion: We have excellent results in 10 cases $(33.33 \%)$, good in 11 cases $(36.67 \%)$, fair in 7 cases $(22.33 \%)$ and poor in two cases $(6.67 \%)$ according to the Harris hip rating system. We got excellent to good results in $70 \%$ of the cases at a mean follow up period of six months. We analysed pain at 6 weeks, 3 months and 6 months follow up according to Visual analogue scale (VAS) in all patients. At 6 months follow up period, $70 \%$ patients had no pain (0), $20 \%$ had mild pain (1-4), $6.67 \%$ moderate pain $(5-8)$ and $3.33 \%$ severe pain $(>8)$. Early assisted ambulation was begun on second post operative day in our study, which probably accelerated better functional recovery. At 6 months follow up period, $70 \%$ patients were ambulatory without assistance, $23.33 \%$ patients were ambulatory with assistance (with cane).

Conclusion: We came to a conclusion after treating 30 patients of intracapsular fracture neck of femur, with Bipolar prosthesis, that it has better advantage in terms of stability, mobility, range of motion, and functional outcome as per Harris hip score.

Keywords: Intracapsular fracture neck, bipolar prosthesis, Harris hip score, hemiarthroplasty

\section{Introduction}

Hip fractures are common and comprise about $20 \%$ of the operative workload of an orthopedic trauma unit ${ }^{[1]}$. As life expectancy is increasing all over the world Geriatric population sustaining the Fracture neck of femur are also increasing resulting in Great burden to health of society which can be better managed with Hemiarthroplasty ${ }^{[2]}$. The estimated annual cost of treating these fractures is a significant burden to any healthcare system. As a consequence, proximal femur fractures are a significant cause of morbidity and mortality in all age groups, especially in elderly ${ }^{[3]}$.

Various methods of treatment have been employed since ages. The prolonged immobilization in elderly, will further lead to decubitus problems and associated complications, and hence surgery was resorted to achieve early ambulation. It is known fact that the hip is a weight bearing joint performing many functions.

Hemiarthroplasty (Unipolar or Bipolar) is the most common treatment for displaced fractures of the femoral neck in the elderly and is associated with better functional outcome and fewer reoperations than internal fixation ${ }^{[7,8]}$.

Hemiarthroplasty is associated with greater initial operative trauma but has a lower risk of implant failure requiring reoperation of the hip than internal fixation, making it a cost-efficient treatment $[9,10]$. At present the choice of treatment is best determined by patient factors (including age, presence of arthritis, availability and cost of the different types of treatment,

\section{Correspondence}

Professor, Department of Orthopedics, Navodaya Medical College, Raichur, Karnataka, India 
surgeon experience and preference) ${ }^{[11]}$. The goal of the current study is to assess the functional outcome and quality of life in terms of pain, mobility, stability using Harris Hip Score in the 30 patients with intracapsular femoral neck fracture, admitted to the Department of Orthopaedics, Ashwini Hospital, Gulbarga and treated with bipolar hemiarthroplasty.

\section{Aims and objective of the study}

To study the results of bipolar prosthesis with respect to pain, mobility and stability and to analyze the complications peroperative and post operative like infection, DVT, acetabular erosion, loosening and dislocation.

\section{Materials and methods}

The prospective study included thirty patients with intracapsular femoral neck fractures referred to the Department of Orthopaedics, Ashwini Hospital, Gulbarga were selected for this study. Patients with intracapsular femoral neck fractures and aged above 55 years were considered. Patients below 55 years of either sex presented with femoral neck fracture associated with either acetabular or lower limb fracture or deformity of knee or ankle joint were not considered for the study. After finding the suitability as per inclusion and exclusion criteria, patients were selected for the study and briefed about the nature of the study, the interventions used and written, informed consent was obtained. Further, descriptive data of the participants like name, age, sex, detailed history, were obtained by interviewing the participants and clinical examination and necessary investigations were recorded on predesigned and pretested proforma.

\section{Results}

The present study consists of 30 cases of intracapsular fracture neck femur treated surgically by Bipolar hemiarthroplasty. Following are the observations made. Long term follow up could have helped further with better results.

Table 1: Prosthesis used in this study

\begin{tabular}{|c|c|c|c|}
\hline \multirow{2}{*}{ Head size in mm } & \multicolumn{3}{|c|}{ No. of Patients } \\
\cline { 2 - 4 } & Total & Males & Females \\
\hline 39 & 02 & 0 & 02 \\
\hline 41 & 09 & 0 & 09 \\
\hline 43 & 04 & 0 & 04 \\
\hline 45 & 08 & 05 & 03 \\
\hline 47 & 04 & 04 & 0 \\
\hline 49 & 03 & 03 & 0 \\
\hline Total & 30 & 12 & 18 \\
\hline
\end{tabular}

The size of the prosthesis used in this study ranged between $39 \mathrm{~mm}$ to $49 \mathrm{~mm}$. In 9 patients $41 \mathrm{~mm}$ bipolar prosthesis was used, while in 8 patients $45 \mathrm{~mm}$ prosthesis was used.

Table 2: Cemented or Uncemented prosthesis

\begin{tabular}{|c|c|c|}
\hline Type of prosthesis & Number & Percentage (\%) \\
\hline Cemented & 12 & 40 \\
\hline Uncemented & 18 & 60 \\
\hline Total & 30 & 100 \\
\hline
\end{tabular}

Out of the 30 Prostheses used in surgery, majority were Uncemented type (18 patients) accounting for $60 \%$. Remaining 40\% (12 patients) were cemented.
Table 3: Intra-op Complications

\begin{tabular}{|c|c|c|}
\hline Complication & Number & Percentage (\%) \\
\hline Periprosthetic fracture & 01 & $3.33 \%$ \\
\hline Difficulty in extraction of head & 01 & $3.33 \%$ \\
\hline
\end{tabular}

We faced difficulty in reduction of prosthesis while inserting cemented bipolar prosthesis in one patient, leading to peri prosthetic fracture as a complication (3.33\%) which was managed by circlage wiring. In another patient we faced difficulty while extraction of head, as there was soft tissue contracture (patient was operated after 16 days of admission).

Table 4: Post-op Complications

\begin{tabular}{|c|c|c|}
\hline Post-op complications & Number & Percentage (\%) \\
\hline Superficial infection & 02 & 6.67 \\
\hline Lengthening $(1-2 \mathrm{~cm})$ & 02 & 6.67 \\
\hline Pressure sore & 02 & 6.67 \\
\hline
\end{tabular}

Two patients $(6.67 \%)$ had superficial infection which was treated with I.V antibiotics according to the culture and sensitivity report of the pus. Two patients $(6.67 \%)$ had limb lengthening of $1.5 \mathrm{~cm}$. Two patients developed pressure sore which healed after one week.

\section{Follow-Up Period}

All the patients were followed up at 6 weeks, 3 months and 6 months.

All patients were evaluated as per Harris Hip Score. Complications like dislocation, acetabular erosion, loosening of prosthesis were also assessed in follow up visits.

Pain was evaluated using a visual analogue score. A score of 0 represented no pain, while a score of 1 to 4 represented mild pain. A score of 5 to 8 represented moderate, persistent pain and a score $>8$ represented debilitating pain.

Mobility was evaluated as ambulation without assistance, ambulation with the assistance.

Ambulation with the assistance of either a cane or a walker and the ability to climb and descend stairs. Stability of prosthesis was assessed as stable or unstable

Table 5: Delayed Complications

\begin{tabular}{|c|c|c|c|}
\hline $\begin{array}{c}\text { Follow up } \\
\text { period }\end{array}$ & $\begin{array}{c}\text { Acetabular } \\
\text { erosion }\end{array}$ & $\begin{array}{c}\text { Loosening of } \\
\text { prosthesis }\end{array}$ & Dislocation \\
\hline 6 weeks & 0 & 0 & 0 \\
\hline 3 months & 0 & 0 & 1 \\
\hline 6 months & 0 & 0 & 0 \\
\hline
\end{tabular}

One patient presented with dislocation of prosthesis at 3 months follow up period, and it was neglected type of dislocation so it was converted as Excision arthroplasty after removal of prosthesis, considering poor medical condition and compliance of the patient.

Table 6: Evaluation of pain Visual analogue score (0 to 10)

\begin{tabular}{|c|c|c|c|c|}
\hline $\begin{array}{c}\text { Follow up } \\
\text { period }\end{array}$ & $\begin{array}{c}\text { No pain } \\
(\mathbf{0})\end{array}$ & $\begin{array}{c}\text { Mild pain } \\
(\mathbf{1 - 4})\end{array}$ & $\begin{array}{c}\text { Moderate } \\
\text { pain (5-8) }\end{array}$ & $\begin{array}{c}\text { Severe pain } \\
(\mathbf{8})\end{array}$ \\
\hline 6 weeks & $12(40 \%)$ & $10(33.33 \%)$ & $6(20 \%)$ & $2(6.67 \%)$ \\
\hline 3 months & $17(56.67 \%)$ & $7(23.33 \%)$ & $4(13.33 \%)$ & $2(6.67 \%)$ \\
\hline 6 months & $21(70 \%)$ & $6(20 \%)$ & $2(6.67 \%)$ & $1(3.33 \%)$ \\
\hline
\end{tabular}

At 6 months follow up, 21 patients $(70 \%)$ had no pain, 6 patients $(20 \%)$ had mild pain, 2 patients $(6.67 \%)$ had moderate pain and 1 patient $(3.33 \%)$ had severe pain. 
Table 7: Evaluation of Mobility

\begin{tabular}{|c|c|c|c|}
\hline Follow up period & Ambulation without assistance & Ambulation with assistance (Walker/Cane) & Non ambulatory \\
\hline 6 weeks & $7(23.33 \%)$ & $20(66.67 \%)$ & $3(10 \%)$ \\
\hline 3 months & $18(60 \%)$ & $10(33.33 \%)$ & $2(6.67 \%)$ \\
\hline 6 months & $21(70 \%)$ & $7(23.33 \%)$ & $2(6.67 \%)$ \\
\hline
\end{tabular}

3 patients were non ambulatory even with assistance at 6 weeks follow up period.one patient with ipsilateral distal end radius fracture, one patient with peri prosthetic fracture (intraop complication) and another patient with poor general condition and weakness.

- 2 patients were non ambulatory at 3 months follow up even with assistance. One patient with periprosthetic fracture and another who presented with dislocation. These two patient were non ambulatory even at 6 months follow up period.

Prosthesis was assumed to be stable if there was no dislocation or loosening of prosthesis in x-ray.

Table 8: Evaluation of Stability (Prosthesis)

\begin{tabular}{|c|c|c|}
\hline Follow up period & Stable & Unstable \\
\hline 6 weeks & 29 & 1 \\
\hline 3 months & 28 & 2 \\
\hline 6 months & 28 & 2 \\
\hline
\end{tabular}

At 6 weeks follow up, prosthesis was unstable in one patient who had have periprosthetic fracture intra operatively. Another patient presented with dislocation of prosthesis at 3 months follow up period, which was converted as Excision arthroplasty, these 2 patients accounted for unstable prosthesis in follow up period.

Table 9: Outcome: Harris hip score (at 6 months)

\begin{tabular}{|c|c|c|}
\hline Outcome & Number & Percentage (\%) \\
\hline Excellent & 10 & 33.33 \\
\hline Good & 11 & 36.67 \\
\hline Fair & 07 & 23.33 \\
\hline Poor & 02 & 6.67 \\
\hline
\end{tabular}

Harris hip score was used to evaluate the functional results. Using this rating scale at sixth month, based on range of motion, shortening $(\mathrm{cm})$, pain, walking ability, stair climbing and return to work, there were 10 patients $(33.33 \%)$ with excellent results, 11 patients $(36.67 \%)$ with good results, 7 patients $(23.33 \%)$ with fair results and 2 patients $(6.67 \%)$ with poor outcome.

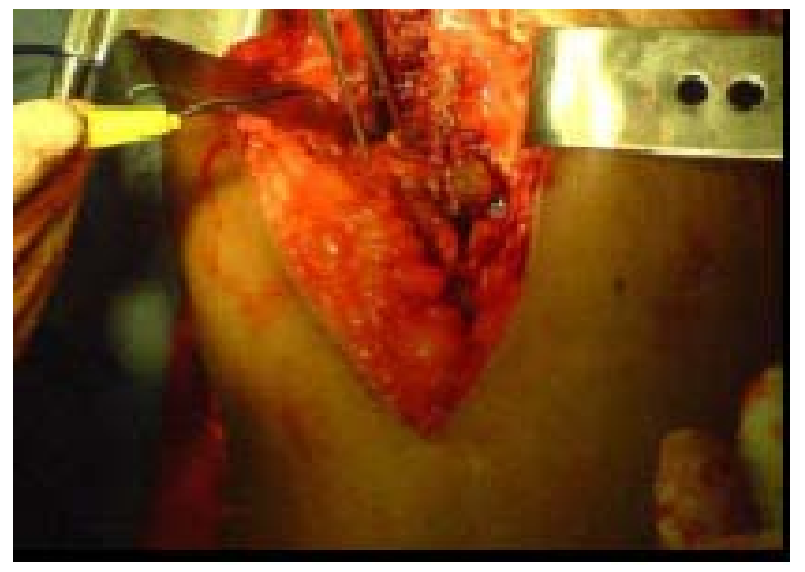

Exposure of the neck

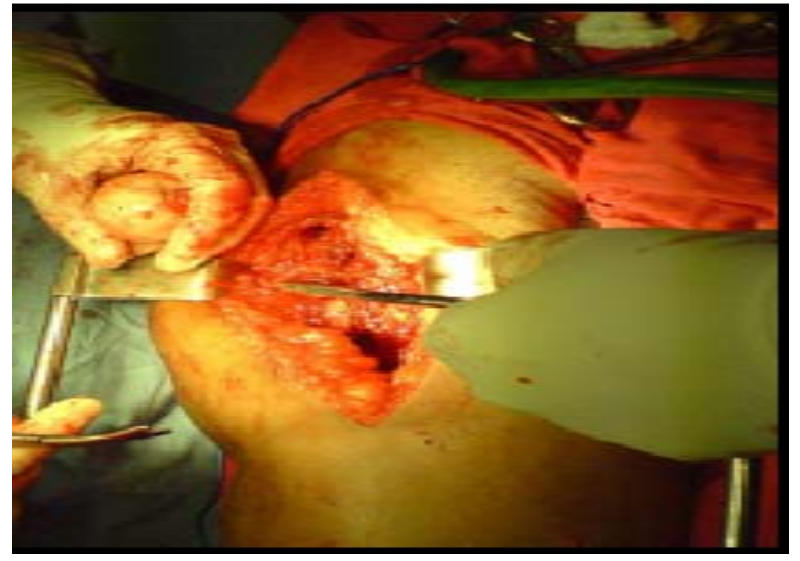

Extraction of the head

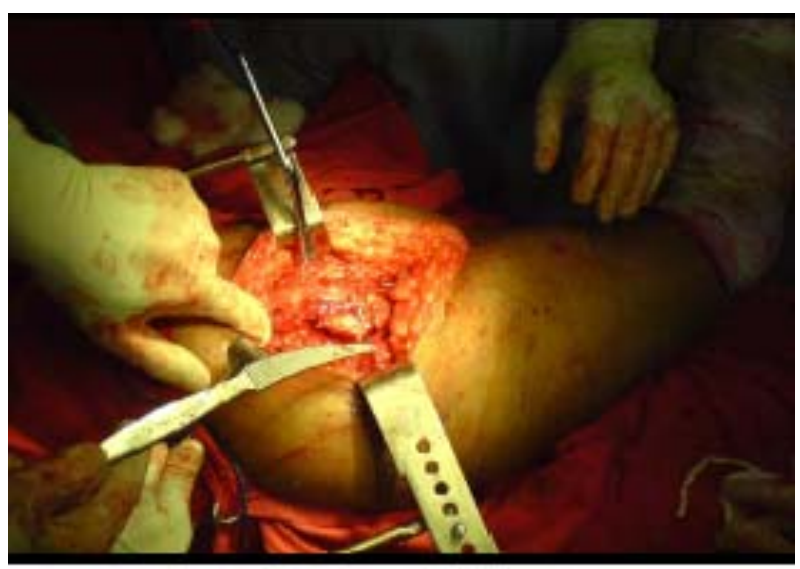

Reaming the medullary canal

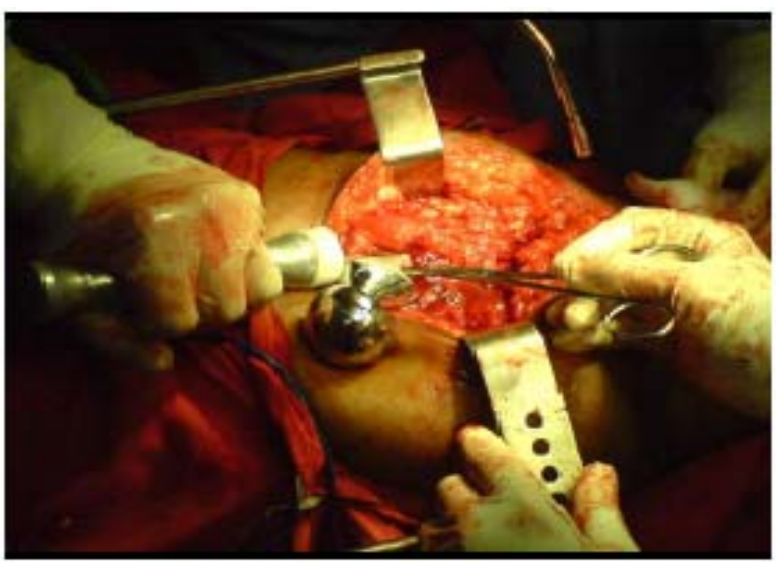

Seating of the prosthesis

\section{Discussion}

In our study of 30 cases of intracapsular fracture neck of femur in the age group of 56-86 years, managed by Bipolar hemiarthroplasty, we have excellent results in 10 cases (33.33\%), good in 11 cases $(36.67 \%)$, fair in 7 cases $(22.33 \%)$ and poor in two cases $(6.67 \%)$ according to the Harris hip rating system. The two patients with poor results included a 
male with periprosthetic fracture and another female aged 73 yrs who presented with dislocation of prosthesis and was bed ridden due to poor medical conditions. We got excellent to good results in $70 \%$ of the cases at a mean follow up period of six months. In the reported series, Giliberty (1983) had 92\% satisfactory results with a mean Harris hip rating of 84.81 points, Mannarino et al (1986) had mean Harris hip score of 84.7 points, Lausten et al (1987) found 75\% excellent to good results, Lestrange (1990) had $70.8 \%$ excellent to good results. Hennig et al (1991) found results comparable to total hip replacement according to Harris hip score, Lortat et al (1992) found $94 \%$ satisfactory results and substantially better clinical and roentgenographic results as compared with Moore's prosthesis and results comparable to total hip replacement, Surya Bhan (1993) had 90.6\% excellent to good results in bipolar and $77.8 \%$ in Austin Moore group. Our results are quite similar to the above mentioned series. We analysed pain at 6 weeks, 3 months and 6 months follow up according to Visual analogue scale (VAS) in all patients. At 6 months follow up period, $70 \%$ patients had no pain (0), $20 \%$ had mild pain (1-4), 6.67\% moderate pain (5-8) and 3.33\% severe pain $(>8)$. Early assisted ambulation was begun on second post operative day in our study, which probably accelerated better functional recovery. At 6 months follow up period, 70\% patients were ambulatory without assistance, $23.33 \%$ patients were ambulatory with assistance (with cane).

\section{Conclusion}

We came to a conclusion after treating 30 patients of intracapsular fracture neck of femur, with Bipolar prosthesis, that it has better advantage in terms of stability, mobility, range of motion, and functional outcome as per Harris hip score. There is reduced morbidity and mortality, with excellent to good results in $70 \%$ and mean Harris hip score of 84.43 points. In osteoporotic bones or in bones with wide medullary canal where the stem of the prosthesis was found to be loose, we have used bone cement for stabilization of the prosthesis. The prosthesis is cost effective and provides the patients early mobilization with less pain, with a good range of functional movements. We have encountered one dislocation in our series which was due to poor patient compliance as patient was bed ridden and co-morbid conditions. Hence it is a superior implant requiring a simple procedure for fracture neck of femur in elderly patients. With increasing periods of follow up in our study, Harris Hip score improved. We do not have a longer follow up to comment about the longevity of the prosthesis. We feel 30 patients is too small a number to give a statistically significant opinion as the cases were studied for a short period ranging with a mean follow up period of six months.

\section{Reference}

1. Singer BR, McLauchlan GJ, Robinson $\mathrm{CM}$ et al. Epidemiology of fractures in 15,000 adults: the influence of age and gender. J Bone Joint Surg (Br). 1998; $80(2): 243-248$

2. Dennison E, Mohamed MA, Cooper C. Epidemiology of osteoporosis. Rheum Dis Clin North Am. 2006; 32(4):617-629.

3. Serrnbo 1, Johnell O. Changes in bone mass and fracture type in patients with hip fractures. A comparison between the 1950s and 1980s in Malmö. Sweden. Clin Orthop Relat Res. 1989; 286:139-147.

4. Speed Fractures K. 50 year review of teaching and treatment. Illinois Med J. 1952; 102:85-92.
5. Lu-Yao GL, Keller RB, Littenberg B, Wennberg JE. Outcomes after fractures of the femoral neck: A meta analysis of 106 reports. J Bone Joint Surg. 1994; 76(A):15-25.

6. Magaziner JE, Hudson J, Hebel J, Young JR, Hawkes YW et al. Outcome after hemiarthoplasty for femoral neck fractures in the elderly. Clin Orthop. Relat Res. 1998; 348:51-8.

7. Frihagen F, Nordsletten L, Madsen JE. Hemiarthroplasty or internal fixation for intracapsular displaced femoral neck fractures: randomised controlled trial. BMJ. 2007; 335:1251-1254.

8. Parker MJ, Gurusamy K. Internal fixation versus arthroplasty for intracapsular proximal femoral fractures in adults. Cochrane Database Syst Rev. 2006; 4:CD001708.

9. Rogmark C, Johnell O. Primary arthroplasty is better than internal fixation of displaced femoral neck fractures: a meta-analysis of 14 randomized studies with 2,289 patients. Acta Orthop. 2006; 77:359-367.

10. Rogmark C, Carlsson A, Johnell O, Sembo I. Costs of internal fixation and arthroplasty for displaced femoral neck fractures: a randomized study of 68 patients. Acta Orthop Scand. 2003; 74:293-298.

11. Keating JF, Grant A, Masson M et al. Randomized comparison of reduction and fixation, bipolar hemiarthroplasty, and total hip arthroplasty. Treatment of displaced intracapsular hip fractures in healthy older patients. J Bone Joint Surg (Am). 2006; 88:249-260. 